\title{
Esbozo para una etnografía del vagabundo
}

Marcelo Berhó C. Antropólogo.

\section{Resumen}

Este es un intento por revelar, en los términos más cercanos a la realidad, el mundo de las diferencias (y las semejanzas) de lo que pueden llamarse estilos de vida vagabunda. A través de tal acercamiento se pretende dilucidar la condición sociocultural de las personas vagabundas de la ciudad de Temuco y abrir una discusión en torno a las tonalidades y los diversos contornos que proyectan distintas clases de personas vagabundas, sugiriendo que la etiqueta-de vagabundoencierra un universo de vivencias y significados muy heterogéneo que puede revelarse y hacerse inteligible a la luz de la investigación y el trabajo etnográfico.

«sólo la sangre, el nacimiento y las hazañas tenían derecho a la historia», Michel Foucault

Cuando el etnógrafo de campo desarrolla investigación en contextos urbanos y cuando se aboga al estudio sustantivo del estilo de vida de una clase marginal de personas como pueden ser los vagabundos está, casi por encanto, ante una tarea tan densa como cuando debe enfrentarse a una cultura extraña.

Quisiera exponer, como modo de acercamiento hacia un punto de vista que está todavía por construirse, algunas notas, derivadas de una investigación etnográfica exploratoria relativa a la condición sociocultural del vagabundo en Temuco teniendo como telón de fondo las vicisitudes de la práctica etnográfica desplegada y aquellas que impone el proceso mismo de escritura como contexto en el que se hace inteligible la densidad de la vida social de los grupos humanos. Aquí, como en otras partes, se deben usar las grafías de la conducta modelada antes que las convencionales de representación sonora. En este esfuerzo, la empresa etnográfica cobra pleno sentido pues brinda acceso a respuestas dadas por otros a la vez que proporciona una base sobre la cual interpretar lo que otros dicen, piensan, sienten y hacen.

Después de alrededor de seis meses de investigación de campo uno puede estar en condiciones relativas -al menos así se siente- de poder dar cuenta de algunas constantes en la vida cotidiana de aquellos con quienes uno ha entrado en contacto. En este caso, se trató principalmente de lo que puede haber de común en las experiencias y vivencias, las rutinas y todo un cortejo de signos que bullen detrás de las vidas de los vagabundos, o través de las mismas en el contexto urbano de Temuco, en la IX región de la Araucanía -ciudad de apenas más de cien años más o menos turbụlentos, una mezcla de vida pueblerina marcada por el rápido crecimiento económico de los últimos decenios, pero a la vez tremendamente atravesada por los estilos de vida rurales y las relaciones interétnicas y las prácticas de dominación propias de las sociedades asimétricas: así, en Temuco, y en general en la región, confluyen elementos culturales diversos y étnicamente diferenciados, productos de todo un proceso de relaciones más o menos tradicionales que hoy día -y desde el inicio mismo de los contactos- comienzan a transformarse.

En particular, los elementos que identificaré a continuación corresponden al comportamiento simbólico habitual de un grupo de vagabundos de la ciudad, con los que comencé a tener contactos desde Enero de este año -con algunos durante todo este tiempo (unos siete meses)-, viéndolos lo más estrechamente ligados a las circunstancias contextuales, a las atmósferas escénicas y a los tonos de la interacción que establecen. A la vez, estos contextos de observación servirán 
de contextos para la interpretación de algunos trazos significativos del tejido etnográfico, contribuyendo así a dar forma a una etnografía del vagabundo.

Las principales vicisitudes que se derivan de una investigación etnográfica del vagabundo -y que son pistas que sirven para caracterizar al mismo- son simultáneamente del orden de una sensibilidad social que les aplica etiquetas y los acoge o los excluye (en el caso particular de esta investigación, varias son las instituciones y organizaciones que los acogen y les brindan algún tipo de apoyo, pero más abrumador es el número de las mismas que los excluyen o marginan), y de una diferenciación interna casi imperceptible a no ser de que estemos ahí. Estas dificultades de orden empírico llevan consigo aparejado un problema conceptual -y no meramente terminológico-. De modo que uno de los esfuerzos más significativos aquí estará enderezado a distinguir clases de vagabundos y, por lo tanto, a una categorización de los mismos.

En pocas palabras, ese indiferenciado mundo que parece contener la categoría del vagabundo hoy en día puede ser tanto más heterogeneo cuanto más se indaga en las particularidades mismas que hacen la diferencia entre un sujeto y otro. Así, ¿qué tienen en común -si es que tienen algo en común- las personas que a la vez son vagabundos, indigentes, mendigos, adultos de la calle, borrachines inveterados, peregrinos y unos que otros enfermitos? (Obviamente, aunque no siempre podamos advertirlo) cada una de estas etiquetas hace referencia a una que otra condición del sujeto: a veces desde el punto de vista de la posición del mismo en el sistema del trabajo y los vínculos con la sociedad y las normas legales de la misma, otras desde la óptica de los problemas sociales y la salud mental -al menos como la propia sociedad y sus instituciones lo interpreta. Sin embrago, sigue en pie saber quién es aquel cuyo rostro se desdobla según quien se dirige a él.

En esta dialéctica entre lenguaje y realidad considero irremplazable la intensidad con que fulguran las existencias de los propios sujetos, a través de sus voces: «... somos todos de los mismos negros», «la verdad, hermanito, somos todos unos torrantes, todos andamos torranteando», «en la calle hay que ser como perro, bruto», «no se cómo no me he vuelto loco o me he muerto», «nunca pensé que llegaría a estar como estoy ahora, cagao, como animal tirao»; «... años durmiendo al lao de la línea (del tren)... he pasado temporales, barro, frío, humedad... me he meao y cagao en los pantalones»; 《estoy enfermo, pero enfermo de curao!»; «odio a la gente que tiene más que uno, a los ricos, a los que están bien y no están cagaos como uno... en la calle, sin un colchón ni una frazá, con hambre y sin nada que hacer porque nadie te pezca»; «yo estoy así por una mujer estúpida... le tengo odio»; «... antes era caminante, ahora ya no... me quedó aquí no más». Estas son expresiones de los alcohólicos, por decirlo de algún modo. Otro grupo está conformado por aquellos que visiblemente manifiestan un comportamiento psiquiátrico. Aquí el discurso es otro y la situación se percibe de otro modo: «la banca se me quebró»», «yo estoy en el cielo y no vuelvo nunca jamás» -dice en el cuaderno de Pelayo, un vagabundo con todas las de serlo: no tiene casa ni familia ni pensión ni trabajo, usa barbas, lleva el cabello desgreñado, viste lo que le den, de vez en cuando pide, suele deambular por las calles y, sobre todo, se halla aislado de todo lo que signifique comprometerse con los deberes y motivaciones propios de nuestra sociedad-; 0 , como para justificar las andanzas «me dicen que mi casa está encantada y no puedo volver en dos años»; otra boca dice: «soy extranjero, medio gitano»; sólo «el don de las extremidades me mantiene sano, en movimiento y vivo»; «no estoy completo...»», afirma Pelayo.

Mientras el primer grupo tiende a ser más un conglomerado donde se dan algunas relaciones sociales, el segundo representa un grupo de individuos aislados unos de otros. No obstante, en ambos existe todo un mundo construido sobre principios compartidos: las rutinas del día así lo advierten. Inmediatamente después de haber dormido en algún «puesto» de la $\mathrm{Fe}$ ria pinto, en la línea del tren, en «los traperos» (de Emaus), o «por ahí», los hombres hacen uno que otro «pololito» -un trabajo de carga y/o descarga de mercadería, o algún mandado o «favor» hecho a algún feriero, cuando no otros recolectan cartones, pican leña o hacen diversos trabajos pesados-, se van al bar a «hacer la mañana», para, hacia el mediodía, irse al Comedor Comunitario del Hogar de Cristo a almorzar (cuando no, comen lo que les dan o «lo que salga»). Allí, un número importante llega en estado de intemperancia o bien ebrio $\rightarrow$ para que nos de hambre»- el que, ciertamente, se prolonga después del almuerzo y, a veces o generalmente, 
hasta la noche y el día siguiente... La búsqueda de «pololos», de comida, de alcohol y de abrigo son aquí faenas por excelencia sociales, sobre todo si ciertos significados compartidos se expresan a través de ellas: en general un sentimiento de exclusión mezclado con infortunio, derrota y obcecación. Una nota de campo referida al contexto del Comedor permite advertir esto último a lo que me refiero:

En el comedor están los que hablan en estado de plena intemperancia como Raín hoy día (5/5) mantiene un altercado de palabras estruendosas con Estrada; los que, como Epul o don Manuel, resignados sólo comen su comida; los que abandonados a la espera de una pensión o de una herencia -como Dickinson-, callados todavía esperan; en fin, aquellos que, como los pajaritos -y Pelayo parece uno de ellos-, simplemente han llegado hasta acá por la comida...

En otras circunstancias es relevante el hecho de que quienes conocen o (eventualmente) se encuentran en el sistema de vida de la calle, faciliten la entrada al mismo de quienes son recién llegados y aún no se encuentran familiarizados. Las invitaciones a lugares donde ir a dormir, a comer, a buscar «pololos» o a beber es un modo de compartir la experiencia vivida por el que lleva más tiempo en la calle con aquel recién llegado, y de solidarizar con el mismo dándole a conocer el stock de posibilidades y estrategias para poder sobrevivir como vagabundo, lo que de algún modo muestra la capacidad de reproductibilidad de un estilo propio de hacer las cosas y también de verlas -»〉a mí que me dejen vivir así... si uno tiene su ideología personal no va a aceptar que venga otro y le imponga otra ideología», dice Erwin, un antiguo caminante, anclado hace años en Temuco.

Sin decir que el grupo de los vagabundos «alucinatorios» o psiquiátricamente deteriorados no tienda también a reproducir un estilo -muy marcado por una estética del hedor y la suciedad-, este se halla de todas maneras constituido a partir de otros medios. Estas personas prefieren ante todo la soledad, al punto de no comprometerse en situaciones sociales más o menos establecidas en las que tienden a proyectarse determinados roles e identidades -tanto respecto de sus pares como del común de la gente-.
Don Carlos no se junta con los demás del Hogar. Las conversaciones que llega a sostener con los asistentes de allí son enteramente fortuitas y en todo caso casi inentendibles. Tampoco suele beber o llegar bebido al almuerzo -faena comúnmente grupal-. El es más bien solo. Anda solo. Duerme solo. Almuerza solo. Pide solo. Recolecta solo. Hasta habla solo...

$\mathrm{O}$, trayendo a colación otra nota de campo en la que se expresa con relativa elocuencia la proyección de la vida aislada y en soledad del vagabundo «alucinatorio»:

En el tambor de basura de Millahue -frente a la rotonda de Caupolicán, en la salida sur de la ciudad, cerca de los márgeners de la misma- encontré a Clin, recolector «de materiales» por título propio, estaba completamente sumido allí, en medio de un hedor de vinagre y pudrición. Al acercarme a él advertí que eso le produjo una especie de temor: «quién sabe quien pueda ser», diría Clin posteriormente... Al estrecharle la mano para saludarlo, él se demoró un poco y finalmente también lo hizo pero de un modo tan sutil y liviano que me pareció que en esa timidez se sedimentaba mucho tiempo sin que Clin estrechara manos... A medida que íbamos estrando en conversación sobre «el don de las extremediades», las prohibiciones de su tradición, o respecto de sus dotes y virtudes de «poeta, dibujente, medio atleta y de los

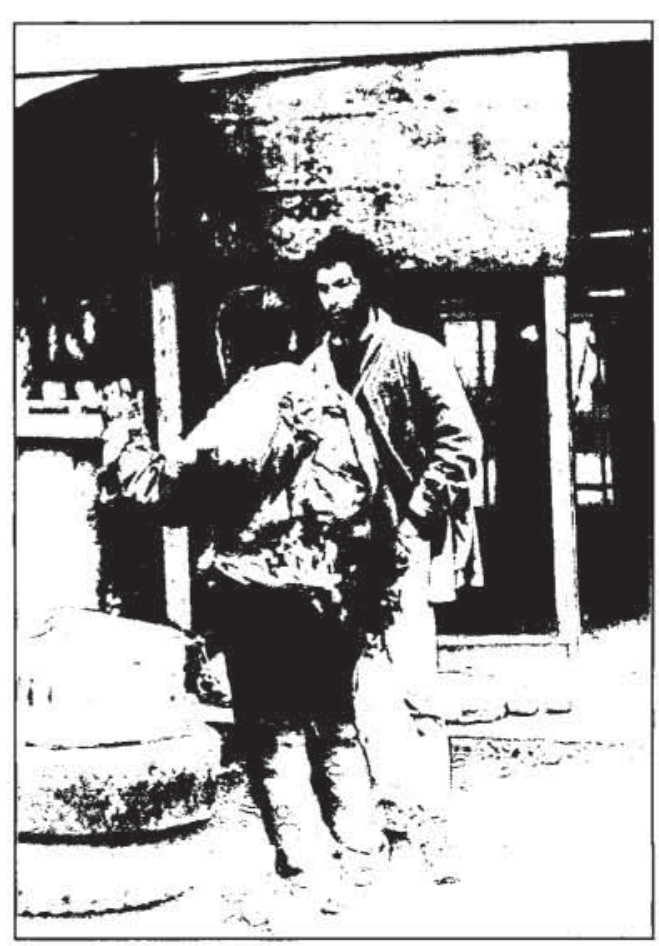
cantares»), y a medida que se me iba haciendo difícil entender qué decía pues hablaba en un tono muy bajo, yo me iba acercando a él -para oir mejor qué decía-y él, a su vez, se iba alejando de mí de tal modo de mantener siempre una distancia... De los muchos aspectos de su vida que Clin me contó esa vez en relación a sus creencias »como gitano y medio extranjero 
que soy no puedo vivir en casa», «como que empiezo a ahogar dentro de la casa»- y, según las observaciones hechas en terreno, las personas de este grupo prefieren estar y andar solas que en compañía, recolectar (comi$\mathrm{da}$, dinero, restos y desperdicios) que pedir, divagar antes que embriagarse. En este grupo no parecen compartirse, pues, estrategias de sobrevivencia: aquí cada cual se las inventa, del mismo modo que cada cual construye su mundo. Hace unos años, cuenta Clin, «sufrí un descambio de fisonomía... empecé a desarrollar el don de las extremidades» -desde entonces él lleva amarrado al cuello y muñecas un collar de cadenas y brazaletes de metal, levanta rocas y vive en el río-. Otro informante Pelayo- cuenta que todavía no está completo y que tiene partes de su cuerpo cambiadas, conoce y maneja el «código de espina» -por medio del que puede saber mentalmente todo lo que desea, por ejemplo como hizo con mi nombre y el de un acompañante, en una ocasión, o como diariamente lo hace para determinar cualquier inquietud que le sale al paso-. Sin duda estos son mundos de acceso privilegiado sólo para quien así lo va determinando. Aquí el mundo de las normas sociales de acción y el mundo de los objetos externos cede paso al de las construcciones privadas y subjetivas, canalizadas por medio de códigos y significados excéntricos: cada cual da rienda suelta a los poderes de la imaginación y el delirio.

Si quisiera, por otro lado, caracterizar el tipo de contextos en los cuales poder constatar vívidamente aspectos de la vida de estas personas, tendría que partir reconociendo las diferencias anteriores. En el primer caso, la tendencia a cierta gregariedad torna evidente la presencia de vagabundos en sitios como la Feria Pinto, los bares y las «picás» de allí, el Hogar de Cristo y los Traperos de Emaus. En tanto que para el segundo grupo, lo habitual es encontrar individuos solos merodeando cerca de algún basurero, sentados en algún banco de plaza pública, o simplemente caminando con o sin ninguna dirección prefijada. Ambos tipos de comportamiento habitual son sólo la superficie de estructuras de acción simbólica de las cuales todos -aunque, por supuesto, no faltan los incorregibles-1legamos a sentir su fuerza como dispositivos de acción modelada. El contraste de superficie recién caracterizado muestra a un nivel más profundo las formas sociales que entran en cuestión cuando la participación no se desarrolla según los esquemas socialmente legitimados de acción social y dentro de los espacios positivamente percibidos. Las categorías como «borrachos», «vagos», 〈〈mendigos» e «indigentes» y sus respectivos escenarios como bares, cantinas, calles y esquinas, caminos, etc. así parecen advertirlo. Pero sobre todo se reconocen al nivel de la persistencia de ciertos usos y prácticas: el uso de barbas y de atuendos para vestir tomados de distintos lugares, o la costumbre de no lavarse y peinarse -en el caso del grupo más desvinculado-,; el embriagarse y andar ebrio a cualquier hora del día -»si no me viene la epilepsia»-, el cambiarse de ropa de vez en cuando - >>cuando se rompe o está muy mugrienta»-, el peinarse y laverse las manos antes de entrar a comer, en el otro, son comportamientos que señalan ciertos extremos de un estilo de vida próximo a crear una grieta casi inzanjable entre el mundo privado de cada uno y el mundo de la vida social -entre máximas de libertad y normas de control-.

Dentro de una jerarquía de la exclusión, el grupo de los alucinatorios estaría en la base misma inmediatamente seguido por el de los alcohólicos. Estos últimos representarían desórdenes corregibles por la vía de la voluntad y la autoconsciencia, en tanto que los primeros encarnarían esa especie de personas que Foucault (1964, 1967, 1994) identifica con el nombre de insensatos -los cuales han sido abordados y examinados con las tácticas del internamiento, la camisa de fuerza y recientemente de la farmacología-. Entre los «curaitos» aún existen como resabios de otra vida, pautas de conducta ritual e interacción ritual -como diría Goffman (1964, 1970), en mayor medida que entre los alienados.

Esto es así a menos que se compliquen más las cosas. Y, de hecho, así ha sucedido al nivel etnográfico con un grupo de personas que, pareciéndose en muchos aspectos objetivables a los hasta aquí brevemente caracterizados -adoptando el tipo de economía basado en la recolección o la mendicidad; durmiendo y deambulando en «los traperos», en los «puestos» de la Feria, hasta hace algún tiempo en los edificios de impuestos internos -frente a la Plaza de Armas!-; prácticamente sin parientes, familiares o amigos que ayuden; sin acceso a los servicios públicos más importantes como salud, vivienda y asistencia-; «con lo puesto» -no hay ropa que mudarse»-; provenientes de otras ciudades y con vidas pasadas marcadas por una mejor situación -»łahora no soy ni la cuarta parte de lo que antes era», «antes tenía plata... para cualquier cosa tenía»; 
«en el campo yo era rico, tenía animales, comida, no me faltaba nunca nada», «era electromecánico y me quedaba tiempo para tocar la guitarra», «tenía mi vehículo, una camioneta», «arreglaba motos y llegué a tener la mía propia, una BMW»; «cuantas mujeres no tuve», «era director de una escuelita», «todos me querían, mi familia, mis padres, mis hermanos»...-; aun así, no hay que confundir a estas personas con la totalidad de los vagabundos. De hecho, este es un grupo que se distingue del resto principalmente en que no existe tanto alcoholismo -algunos no beben y los que lo hacen no son viejos en eso: lo hacen más bien con propósitos estratégicos como para poder dormir a la intemperie, o de vez en cuando se les convida-; todavía se conserva una preocupación por «la buena presentación» y el aseo personal y, de manera muy especial, se ponen en práctica verdaderas reglas de buen proceder, lo que se hace más evidente por el hecho de tener más preparación en el sistema de educación formal y haber tenido una familia bien constituida.

Con este grupo, el de los alcohólicos y «torrantes» -como varios si no la mayoría se han definido a sí mismos- deja de ser un grupo cuya posición está al otro extremo del continuo vagabundo, para establecerse más bien como grupo intermedio entre los «alucinatorios» y los más sobrios de todos, los que con especial intensidad y carácter conservan más rasgos del hombre común y corriente. Una nota personal permite captar el significado de estas diferencias.

Me pareció muy relevante el que Dickinson se preocupara tanto de su aseo y presentación personal »no tolero andar todo cochino, con las manos mugrientas y las uñas negras... y más encima borracho, no», dijo Dickinson refiriéndose a los «peregrinos» que van a almorzar al Comedor del Hogar de Crișto-. De hecho, Dickinson me habló de sus preferencias cuando de usar algún sanitario se trata: «los del INP son los más limpios» y «además no cobran nada». «Los baños de la plaza están inmundos, al igual que los de Emaus». Al comparar la presentación física y el cuidado de la apariencia -junto con el del cuerpo (Dickinson hace dieta)de Dickinson con el de Estrada se pueden descubrir diferencias estilísticas muy profundas: en el primero, la preocupación por «andar bien», limpio y «bien presentado» señala un valor cuyo significado último tiene que ver con una definición del yo distinta a la que tiene el sudoroso y beodo de Estrada -que, como me ha dicho, ha pasado meses sin tocar ni ver siquiera el agua.

Mantener una imagen decente y proyectarla como tal expresa un deseo por no desvirtuarse a nivel de la identidad del yo social; desdibujarse es, a la inversa, proyectar una imagen estigamatizante -por medio del mal olor, el mal aliento, la suciedad y el desgreñamientodel sí mismo social, a la vez que tener más acceso al nivel de lo que los interaccionistas simbólicos entienden como el self espontáneo. Al lado de ambas identidades -y esta es la situación de muchos «allís-late aquella que todavía no ha creado del todo inconsistencias entre una vida infame y llena de desgracias y la que aún se halla movida por disposiciones socialmente compartidas y culturalmente interiorizadas.

Por lo tanto, una caracterización de los contextos de acción e interacción de los vagabundos corresponde a una caracterización diferencial según no sólo por que en cada uno (de los contextos) se presenten distintas clases de vagabundos sino porque el lugar en que cada uno escenifica sus rutinas se encuentra -de un modo que hay que todavía conocer- ligado a las identidades de cada clase. Muy burdamente diría que dependiendo del vagabundo los contextos se pueden perfilar como:

1) aquellos en los que sólo los «alucinatorios» divagan -como calles, sitios eriazos, puentes, cerros basureros -escenarios en los cuales la vida solamente puede transcurrir, como los transeuntes que pasan, la brisa que atraviesa, el agua debajo de los puentes y los desechos que durante la semana se acumulan-;

2) los tugurios o «bajos fondos» en los que reinan las jornadas sin gloria, el detalle sin importancia, el vicio y todo un enjambre de pequeñas desviaciones de conducta -los bares y cantinas del barrio Estación en los que la vida se va dañando, los «puestos» de la Feria, la línea del tren, un auto viejo, etc. en los que el cuerpo se va deteriorando-;

3)aquellos en que sólo se permite a quienes lucen un rostro todavía sin desvirtuar -como establecimientos públicos, tiendas y negocios y lo que equivale al sector más céntrico de la ciudad -donde la vida consiste en un constante mantener ciertas reglas de juego válidas para todos, incluso para los esposos engañados o abandonados, los de fortunas dilapidadas y los exiliados; 
4) aquellos escenarios como Emaus, el Hogar de Cristo y una que otra iglesia en los que, independientemente de quien específicamente se trate, se proporcionan algunos servicios y se brinda apoyo a todos quienes lo requieran -sitios en que la vida infame tiende a reproducirse o al menos en los que bulle con una intensidad de fatalismo e infortunio.

Así, pues, una etnografia del vagabundo corresponde a un examen fino que parte de los aspectos y conductas que las personas excluidas y más o menos desarraigadas de sociedades como la nuestra presentan en diversos escenarios de acción e interacción. Este examen permite, junto con el cuestionamiento sistemático de la presencia misma del vagabundo -y de uno mismo- en la vida cotidiana y el paisaje urbano, una entrada al mundo de las identidades y las diferencias de y entre clases de personas; es, por otra parte, la puerta de acceso para el reconocimiento de contextos de acción e interacción profundamente marcadas por la miseria y la desventura, cuando no por la locura y la obsesión. Un esfuerzo de este tipo requiere un seguimiento inagotable de las personas en sus propios ambientes naturales; requiere tomar consciencia de las mismas, indagar en sus biografias personales y en las fuerzas a las que constantemente se hallan expuestas las personas, visualizar los límites de las mismas en el espacio, marcar sus contornos, referirlas a sus contextos; aprehender las atmósferas y el significado de las conductas que allí se despliegan. Pero, sobre todo, requiere de una paciente y activa observación comunicativa con las personas reales, con los infames, los desarraigados, los insensatos, los excluidos, vale decir, un trabajo sistemático en torno a las asimetrías de la conducta simbólica verbal y no verbal de aquellos socialmente desacreditados. Allí donde el pensamiento y la emoción confluyen por medio de la violencia de las palabras -»si tengo que morir como los perros, moriré como los perros...»-, el etnógrafo -al menos uno mismo- trata de ubicarlas y hacerlas inteligibles dentro de cuadros más o menos completos de conducta simbólica en escenarios no menos dramáticos -el fatalismo de las palabras anteriores fue expresado por Estrada, un alcohólico inveterado, maloliente y «torrante», mientras esperaba que abrieran la puerta del Comedor del Hogar de Cristo, encontrándose él visiblemente en un estado de angustia y desesperación obstinada - $>$ no hay nada que me haga cambiar...»-, nostálgico y consciente del papel de su sí mis- mo en lo que le ocurre - $>$ sufro porque yo mismo me lo he buscado», diría en ese momento-... estaba saludando alegremente a uno que otro amigo «del ambiente», después de haber pasado seis días hospitalizado debido a un fierrazo que le dieran «unos cauros, por doscientos pesos...» -todavía con una benda, esta vez limpio y afeitado-»»vengo recién saliendo, hermanito», había dicho...

Cada detalle tiene en este caso un significado equivalente a un fragmento de sentido en el que diversos signos llegan en un momento determinado a vincularse prođuciendo efectos de acción (así pueden ser los días de Estrada y de muchos otros como él) y de discurso (así pueden ser expresadas realidades como las vividas por Estrada y otros de su estirpe -y que sólo por su intermedio he podido conocer y ahora compartir). Las circunstancias que envuelven, como invisible niebla, la puesta en escena del vagabundo -un sórdido bar, un basurero putrefacto, un oscuro cuartucho o una calle interminable-, más las fachadas, los gestos, posturas y palabras, junto con la persistencia, vehemencia e intensidad con que allí se proyectan, manifiestan y pronuncian dan pie a una lectura a la vez que a una escritura consistentes con lo mismo. La percepción y constatación del infortunio, la desventura, el desarraigo, la desesperanza, la obstinación, la insensatez y la locura que revisten las vidas de estas personas obliga a la utilización de una retórica que, sin glorificar los desórdenes de la conducta inmediata y la desvinculación social sedimentada, los interprete como tales -es decir, como los grados más bajos y persistentes de lo real. Entender la vida de estas. 'personas es aprender a entender la violencia de sus palabras, lo descarnado de sus actos y la vehemencia de su intransigencia.

\section{BIBLIOGRAFIA}

FOUCAULT, M. (1994). Historia de la locura, Tomo I y II, F.C.E.

GOFFMAN, E. (1970). La presentación de la persona en la vida cotidiana. Ed. Amorrortu. 